\title{
Analysis of Control Measures for Settlement of Differences on the Problems of Highway Subgrade Widening
}

\author{
Yuyan Wang \\ Chongqing Transportation University, Chongqing, China \\ Email: 493920640@qq.com
}

Received 30 March 2015; accepted 15 May 2015; published 18 May 2015

Copyright (C) 2015 by author and Scientific Research Publishing Inc.

This work is licensed under the Creative Commons Attribution International License (CC BY).

http://creativecommons.org/licenses/by/4.0/

(c) (i) Open Access

\begin{abstract}
The study mainly discusses the issues of the settlement of differences that occurs in the process of highway subgrade widening. Firstly, it briefly introduces the settlement of difference and its harms; then it analyzes the mechanism of settlement of differences in the process of difference widening, including four aspects: the new and old roadbeds themselves, design, construction and other links; finally, based on the above analysis of the mechanism, it discusses the corresponding control measures, mainly proposing these suggestions as followings: the use of lightweight materials, the foundation treatment, the cut slope excavation steps, and the strict control of the degree of compaction, etc. The paper is expected to provide some theoretical basis for the control measures of highway subgrade widening settlement of difference.
\end{abstract}

\section{Keywords}

Road Widening, Settlement of Difference, Mechanism, Control Measure

\section{Introduction}

In recent years, with the rapid growth of China's economy, the traffic volume of highway grows as well. The capacity of the original two-way four lane highway has been unable to meet the demand, and many old roads will be widened and reconstructed. The settlement of difference is difficult to avoid. The roadbed settlement not only affects driving quality of highway, but also will cause traffic accidents easily, therefore it's particularly important to take reasonable measures to control the difference between new and old subgrade settlements in the design and construction process. 


\section{Introduction of the Main Harms of Settlement of Difference}

Settlement of difference is also called uneven settlement, and it refers to the difference of two basic adjacent settlements in the same structure. It's an important index of the degeneration characteristics of civil engineering structure foundation [1].

For widening the road, the main problem is the settlement difference between the new and old roadbeds, leading to sub grade cracks between new and old. The main structural failure types are pavement and subgrade damage. On the one hand, after years of operation, subgrade settlement has basically been stabilized, due to reasons such as that the new roadbed consolidation will produce larger settlement, so as to cause the settlement of difference. It will make the pavement structure generate additional stress, and when the additional stress and vehicle load are beyond the bearing capacity of pavement structure, pavement structural damage will occur, and even crack. Especially in the combination part of the new and old roadbeds, settlement of difference is large, the additional stress is also great, and longitudinal cracks in the pavement are extremely easy to take place.

In addition, the additional stress caused by the additional settlement in the old roadbed in different positions is different, when the load press on the old roadbed edge, it will make the old foundation become deformed. When loaded in long-term repeated action, it will be the development of pavement crack, fracture, dislocation and other harms. In the water infiltration, pavement damage is accelerated, and there will be boiling or pumping phenomenon.

On the other hand, due to contact with the new and old roadbeds, subgrade is not close enough as well as poor integrity, leading to the settlement deformation. Slip will occur in the embankment of new and old roadbed combination part and even the collapse of unity. When the slippage or collapse of unity is huge, damage will occur when widening the road and overall, leading to the instability of original roadbed, the damage of whole pavement structures, and the lose of traffic safety.

\section{Analysis of the Mechanism of Settlement of Difference}

\subsection{Difference between New and Old Subgrade Subsidence}

Under the same load, for the old road, consolidation deformation of foundation soil has been basically completed, strength is high enough, settlement is small; but the compressibility of soil under the new roadbed is large, it can continue consolidate for a long time, and it will cause bigger settlement, thus makes the new and old roadbed deformation coordination. On the other hand, the new and old roadbeds are different in filler, strength and thickness. Settlement in its load is not uniform, resulting in transverse settlement of difference [2].

\subsection{The Subgrade Design}

For the freeway widening project, there has not been a splicing technology related to the design of our country, it's often based on the engineering experience to determine the step size, old subgrade excavation and slope cutting processing. In the actual constructions, there are basically no rules. Therefore, the design scheme exists some unreasonable and imperfect places inevitably, leading to deepen the new and old subgrade settlement unevenly. In addition, the incomplete consideration of the design part of subgrade drainage as well as the unreasonable drainage facilities may also aggravate the harms of subgrade and pavement.

\subsection{The Subgrade Construction}

Because of the construction of the combination part of the new and old roadbeds during the Widening engineering is complex and difficult, and it's easy to decrease the construction quality, thereby causing settlement of difference harms. Specific performance as follows: 1) the rolling compaction is not meet the standard, so as to the compaction degree is not meeting the design requirements, and the actual settlement of difference is too large; 2) the department of subgrade treatment is not thorough, impurities decay and deteriorate after the embankment forming, and causing joint surface become weak, uneven settlement of foundation is soft; 3) lack of construction machinery, in the course of the construction of subgrade construction machinery, due to the improper configuration, which makes the construction effect not able to meet the requirements of design of the roadbed; 4) in order to save time, constructing in adverse weather may also make the engineering quality reduce due to the difference of settlement. 


\subsection{Other Aspects}

In addition, other factors which will cause the settlement of difference of subgrade widening may contain as follows: a poor geological conditions in widening project like thick soft soil layer; a inattentive project management; the overloading of vehicles; insufficiency of subgrade maintenance.

\section{Method to Control the Settlement Difference}

\subsection{Using the Lightweight Filler}

The use of lightweight filler in general engineering, filling of the embankment filling density is mainly for 19 $\mathrm{KN} / \mathrm{m}$, the use of lightweight filler can reduce weight so as to reduce the settlement of the roadbed, and ensure the stability of the roadbed. Light filling subgrade mainly includes fly ash and EPS (polystyrene foam) and so on. Flying ash is filtered from the ash that discharges from the coal, its severe is $10.7-11.0 \mathrm{KN} / \mathrm{m}$, and it can effectively reduce the weight and protect the environment. EPS is a light high polymer. Used in the highway construction of lightweight filler EPS density is $20 \mathrm{~kg} / \mathrm{m}^{3}$, percent in ordinary road filling $1 \%-2 \%$, and the small Poisson ratio, elastic model of large, low thermal conductivity, with small water absorb ability, good heat insulation, mechanical strength and other characteristics of light quality and higher, in a certain depth of the roadbed replacement can effectively reduce the embankment weight, reduce the additional stress in foundation, reduce the settlement of embankment on soft ground, improving the stability of foundation.

\subsection{Foundation Treatment}

The corresponding treatment measures to different types of foundations, can improve its original performance to reduce the settlement of difference. The methods of soft soil are commonly used: exchange soil layer, powder spray pile, curing agent, grouting, composite foundation and etc. The methods of over wet soil commonly used are: dynamic compaction, replacing reinforcement method, gravel cushion indigenous etc. Through the above methods, we can effectively improve the old and new base soil compaction, and its bearing capacity [3]. In addition, as trying to prevent the settlement of difference from the root, it should make the new foundation soil compaction degree higher than that of the old base soil compaction as far as possible.

\subsection{The Cut Slope with Excavation Step}

In combination part, it can hold back the settlement from the roadbed itself by stratification if taking the method of step excavation, reducing the reaction to the pavement settlement. Because of the influence of soil subgrade slope surface is directly affected by the sleet erosion, plant roots, and original compacted fill will become soft, so we must first according to a certain ratio of slope of cut slope treatment, remove the surface miscellaneous soil, ensure the slope soil strength. In order to ensure the better combination of new and old roadbeds, in the widening of subgrade, the general use of the broken edge gradient of 1:0.5 - 1:1.5, every excavation required for the smooth compaction. Excavation cut slope of the steps, in order to enhance the integrity of new and old roadbeds and its shear capacity, and at each step of the elimination of settlement of the embankment. For the step excavation, we must satisfy the sufficient height and width first, expressway widening engineering step excavation is generally in the $80 \mathrm{~cm}$ range, but the width depends on the cutting slope, and it's generally in the range of $50 \mathrm{~cm}-200 \mathrm{~cm}$ [4].

Secondly, the dip angle of the step must also meet certain requirements. Inclination is generally adopted in engineering at the range of $2 \%-4 \%$, and the specific choice of parameters depends on the actual situation of engineering. The degree of compaction of the excavation steps have to be the same with the new roadbed compaction degree, itself does not have settlement. In the rolling process, we should pay special attention to the tip of the strip position where we cannot thoroughly clean the plant root since the degree of compaction is the worst. In addition, in the process of excavation, it should edge filling and edge excavating meanwhile in order to ensure the old edge slope stability. On the steps required to be qualified after rolling, we should laying georgic in full step and a certain new subgrade scope to improve its carrying capacity (Figure 1).

\subsection{Control the Degree of Compaction Strictly}

The junction between new and old subgrade compaction degree will directly affect the settlement of subgrade, 


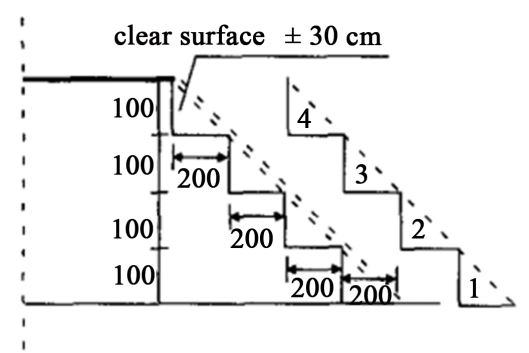

(a)

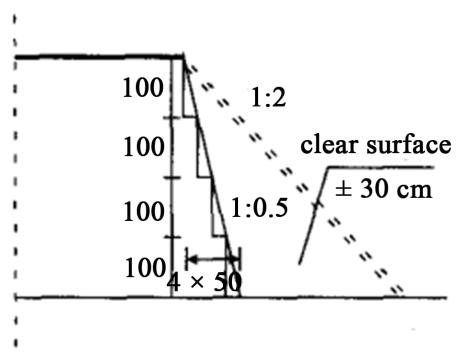

(b)

Figure 1. Schematic diagram of two kinds of construction methods. (a) Cutting slope before excavate; (b) Direct excavation.

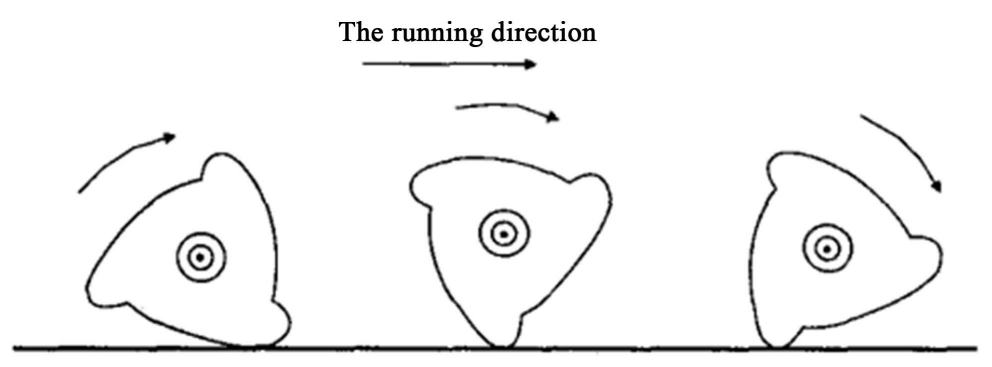

Figure 2. Schematic diagram of construction about impact rolling.

the key of compaction is guaranteed for the stability between new and old subgrade for subgrade widening. Only the old and new embankment with the same degree of compaction can ensure the integrity and strength of subgrade widening, reduce settlement of difference. The process of subgrade compaction is exerting a force on the filler by compacted machinery specialized, and making the filler moved, rearrange, and more compact [5].

The general methods of subgrade compaction are static compaction, vibratory compaction, tamping compaction and impact compaction [6]. For widening subgrade, construction of static rolling and vibration road roller in existing objectively are hard to fully meet the requirements of widening subgrade and to overcome differences in deformation. While the impact compaction has great impact energy, it can increase the influence of depth, improve soil compaction, and achieve the soil elastic state more easily. Therefore, in widening engineering, improvement of subgrade impact compaction can not only have a better compactness and integrity, but also can accelerate the speed of new subgrade settlement (Figure 2).

\subsection{Else}

Measures of subgrade settlement control in highway widening also include adding steel bar to the combination part of the new and old roadbeds, equally loaded and overload preloading and setting a retaining wall, anti pressure beam, waterproof layer and surface drainage facilities and so on.

\section{Conclusion}

There are still many factors that contribute to the differential settlement of widening road, calling for a further refinement. For instance, the influence of rain requires further research and control. In conclusion, research on technology of widening highway is of vital importance on the practical significance and the prospect.

\section{References}

[1] Grant, R., Christian, J.T. and Vanmarcke, E.H. (1974) Differential Settlement of Buildings. Journal of the Geotechnical Engineering Division, 100, 973-991.

[2] Jia, H.M., Li, X.Y. and Yue, W.M. (2012) Highways Roadbed Disease Expansion Causes Analysis and Prevention of. Construction of Shanxi Building, 38, 154-155.

[3] Akbas, S.O. and Kulhawy, F.H. (2009) Reliability-Based Design Approach for Differential Settlement of Footings on 
Cohesionless Soils. Journal of Geotechnical and Geoenvironmental Engineering, 135, 1779-1788. http://dx.doi.org/10.1061/(asce)gt.1943-5606.0000127

[4] Zhang, Z. (2006) Expressway Cut Fill with the Department of Treatment Technology on. Chang'an University, Xi'an, 14.

[5] Turnbull, W.J., Johnson, S.J. and Maxwell, A.A. (1949) Factors Influencing Compaction of Soils. Highway Research Bulletin, n.3, 1-11.

[6] The People's Republic of China Industry Standard (2006) The Highway Impact Rolling Technology Application Guide. China Communications Press, Beijing. 